\title{
Examining learner perceptions of the introduction of computer-assisted learning in mathematics at a peri-urban school in South Africa
}

\begin{abstract}
This study responds to a national call to improve the outcomes in mathematics in the Grade 12 matriculation examination in South Africa by reporting on the perceptions of learners on the introduction of computer-assisted learning in their mathematics classroom. Three Grade 12 mathematics classes in a peri-urban school in South Africa were visited over a period of four months to observe the inclusion of a computer centre as part of the teaching of mathematics. Learner perceptions were obtained from (1) individual and group interviews and (2) an actual and preferred version of a learning environment instrument called the ComputerAssisted Learning Environment Questionnaire (CALEQ), which was developed for the South African context. The learners indicated that they considered application of computers as a positive step as it (1) increased their involvement in the mathematics classroom, (2) gave them more exercises in problem solving in mathematics, and (3) provided them the opportunity to assess their own learning. However, a strong recommendation from this response is for more computers to be made available that would allow learners to work individually thereby being able to spend more time on the computer.
\end{abstract}

Key words: Computer-assisted learning • Constructivist • Secondary• Case Study• IT-use $\bullet$ Learner Perceptions $\bullet$ South Africa. 


\section{Examining learner perceptions of the introduction of computer-assisted learning in mathematics at a peri-urban school in South Africa}

\section{Introduction}

In South Africa learners spend collectively in the order of 18000 school hours in their primary and secondary classrooms. Therefore the nature of the interaction in their learning environments is extremely important and would shape their understanding and perceptions of their school experience. It therefore comes as no surprise when learners, years later, hold on to an experience in their school life that had a profound effect on their careers, emotional state, choices and achievements. According to Fraser (1998) a learning environment can be defined as the social, physical, psychological and pedagogical contexts in which learning occurs and which affect learner achievement and attitudes. For more than 30 years learning environment research has been conducted around the world with a range of intentions and outcomes (Aldridge and Fraser 2008). Learning environment questionnaires in past research has largely been used as a measure of the effectiveness in the evaluation of educational innovations (Aldridge and Fraser,2008). In this regard the use of learning environment scales or criteria have highlighted the effectiveness of new educational programmes or approaches, including computer-assisted learning (Maor and Fraser 1996; Teh and Fraser 1994; Buerck et al. 2003; Hakkarainen 2003; Hartley and Treagust 2006), identifying exemplary science teachers (Waldrip and Fisher 2003), assessing distance education (Walker and Fraser 2005), computer courses for adults (Khoo and Fraser 2008) and innovative science courses (Martin-Dunlop and Fraser 2008).

Learning environment research is a fairly recent phenomenon in South Africa. Nevertheless, the Third International Conference on Science, Mathematics and Technology Education held in East London, South Africa in January 2003 revealed an increasing interest in research on learning environments in South Africa (Fisher and Fraser 2003). A number of studies focussed on outcomes-based education (Aldridge et al. 2004; Aldridge et al..2006; Aldridge et al. 2006). In a recent study of 50 classes using the WIHIC (What Is Happening In this Class) as the learning environment instrument to determine whether the nature of the school-level environment influenced the classroom-level environment in South Africa, Aldridge et al. (2011) 
concluded that the overall school environment did not have a strong influence on what happens in the classroom.

This paper examines the mathematics learning environment of a peri-urban school on the outskirts of the Western Cape Province in South Africa and considers the classroom environment in terms of the shared perceptions of the learners and teachers. This experience has the dual advantage of characterising the environment through the eyes of the participants themselves and capturing data which the observer could miss or consider unimportant (Fraser 1998). Learners are at a good vantage point to make judgements about classrooms because they have encountered a number of different learning environments and spend sufficient time in a class to form accurate impressions. According to Fraser (1998), even if teachers are inconsistent in their dayto-day behaviour, they usually project a consistent image of the long-standing attributes of classroom environment.

\section{Objective of this study}

This study describes the learning environment in one peri-urban school on the outskirts of the Cape Town, South Africa, after the introduction of computer-assisted learning and forms a subset of a larger study (Hartley 2002; Hartley and Treagust 2006; Hartley et al. 2008). Of specific interest were the application of computers in the mathematics classroom and the perceptions of Grade 12 learners of computerassisted learning as a new addition to their learning environment.

\section{Data collection procedures}

\section{Classroom observations}

The computer-assisted lessons taught by two teachers were observed through on-site visits during two cycles of two months; the first cycle took place during April-May and the second cycle during July-August of the same year. A total of two weeks was spent during each cycle with 12 lessons observed and recorded, six for each Grade 12 mathematics teacher. The lessons took place both in the normal classroom and in the computer centre depending on the availability of the centre. The medium of instruction in the classroom at this school was English even though the mother tongue of students was overwhelmingly Xhosa. A narrative report of on-site visits was used to describe the application and actual implementation of the computer centres in the 
daily lessons by teachers. The data collection involved observations of lessons, drawing up of field notes and videotaping the use of the computer centre in mathematics lessons and interviews of students and teachers. The lessons and interviews were recorded and coded for cross-reference purposes.

\section{Learner perceptions}

The perception of learners of their CAL classes was established through interviews and the Computer-Assisted Learning Environment Questionnaire (CALEQ). Responses provided in the questionnaire were used as a basis to guide the interviews. The development of the CALEQ was initiated by a search for an instrument that would, firstly, adequately encompass those circumstances unique to disadvantaged schools in South Africa and, secondly, focus on inviting learners' perceptions of their own learning in computer-assisted mathematics and science classes. Guidance in identifying scales was obtained from existing validated and reliable classroom environment instruments which included both computer and non-computer settings. Table 1 represents the scales used in the CALEQ.

\section{PLACE TABLE 1 ABOUT HERE}

CALEQ scales included adaptations to the Involvement scale from the What Is Happening In this Class (WIHIC) questionnaire (Fraser et al. 1996), the OpenEndedness scale from the Science Laboratory Environment Inventory (SLEI) (Fraser et al. 1993), the Investigation scale from the Individualised Classroom Environment Questionnaire (ICQE) (Fraser 1990). The Resource Adequacy scale from the Geography Classroom Environment Inventory (GCEI) (Teh and Fraser 1993) and Organization scale from Computer Classroom Environment Inventory (CCEI) (Maor and Fraser 1993) were modified and items amalgamated to form one scale called the Material Organization scale. The last two scales, namely the Learning Assessment scale and Integration scale were developed by the researcher in order to address specific questions around, in the first instance, learners evaluating their own learning in CAL classes, and in the case of the latter, obtaining learner perceptions around the application and inclusion of computers in the teaching and learning environment. The instrument was constructed in a way that would require a relatively short time to 
complete and hand score, by including a small number of scales (6), each containing a relatively small number of items (8). Each scale ranged from 1 to 5 , with 1 for the most negative perception that represents almost never, 2 represents seldom, 3 represents sometimes, 4 represents often and 5 for the most positive perception, which represents very often. Finally, in order to ensure that both teachers and learners considered the $C A L E Q$ 's scales and items salient, selected teachers and learners from surrounding schools were asked to comment on the preliminary versions of the instrument for face validity, clarity of language and suitability for issues such as culture. Two versions of the CALEQ were developed, namely the actual and preferred formats. The actual format referred to how learners actually perceived their CAL classes whilst the preferred referred to how learners would want (preferred) these classes to be. The Cronbach alpha reliability values used to determine the internal consistency of the CALEQ (see Table 2) for each scale were greater than the 0.5 threshold for small samples proposed by Nunnally (1978) and therefore the instrument was considered acceptable for research purposes.

Learner interviews were held during the second round of on-site visits. Learners' responses on the CALEQ were used as a starting point to gather their perceptions of the inclusion of computers as part of their mathematics lessons. A semi-structured interview approach was used with questions structured around a number of areas, namely, some learner background, learners' experiences about the inclusion of the computers as part of their classes, how they perceived their learning taking place, whether working on the computers improved their understanding of the work, and how the inclusion of computers influenced interactions with their classmates. Learners also were probed about any preferred improvements or changes to their computer-assisted classes. This interview framework was flexible, enabling students to discuss different issues related to their experiences. A total of 37 learners were interviewed consisting of nine individual interviews and five group interviews. The group interviews were conducted with between two and five learners. They were allowed to form their own groups because it appeared from preliminary discussions that learners who were not proficient English speakers responded better in groups. The five groups consisted of one group of two learners, three groups of four learners, and one group of five learners. Two mathematics teachers and the principal were 
interviewed for their perceptions and response to the implementation CAL during the investigation.

\section{Context}

The school was situated in a peri-urban area on the outskirts of Cape Town that was developed by the apartheid government for people of African (black) origin. Very few resources (in terms of libraries, sport, entertainment) and infra-structure (electricity, water, roads) were available to learners in this area because the area consists mainly of informal housing - a so-called squatter area. The school stood out amongst its surroundings as it had the structure of a modern school. Bus and taxis from the surrounding informal settlement areas transported a large number of the learners to and from this school.

On the way to the school, one drove through a number of informal settlements in between which the school was located. The school was surrounded by a high fence with an electronically operated gate guarding the entrance. The entire school was an enclosed structure with all classrooms opening toward the inside of the school and was under one roof. A courtyard (also under the roof) was situated in the middle of the school with the computer centre next to it. This courtyard appeared like a market during lunch-breaks as members of the community sold their food and beverages here. The computer centre, located in a large room almost like a hall, contained 15 computer terminals spaced along three walls. A server from which the Computer Aided Mathematics Instruction (CAMI) program operated supported the terminals. The CAMI software was developed in South Africa around the core Mathematics Syllabus to prepare learners for university entrance. The course was divided into modules in accordance with subject matter, making remedial and enriching work easier. The physical science and mathematics software made provision for the teacher to use different methods in the same class and, if needed, to teach different grades simultaneously. There was more than enough space in this centre to add an additional 30 computer terminals. The school had 1329 learners with 37 teachers. There were three classes in Grade 12 and all three classes had learners who studied mathematics. In total there were 80 mathematics learners. Two teachers were responsible for the teaching of mathematics at Grade 12 level. One mathematics teacher (Mr. U), who was the head of the mathematics and physical science department, held a BSc degree 
and a teacher's diploma (HDE). The other mathematics teacher held a BA degree and a Diploma for Adult Basic Education and Training (ABET). Both teachers had between 10 and 15 years' experience in teaching.

A large number of learners came from different areas outside the immediate informal settlement and were transported by taxis to the school. The ages of the learners interviewed ranged from 18 to 22 years. Nine of the learners interviewed failed at least once in a previous grade and three learners came back to school after working. The informal settlements where learners lived had no access to electricity or direct supply of water and unemployment levels were high. Many learners indicated that they were not living with their parents, but with one of their family members. In many instances parents were living in another province or in rural areas and sent their children to learn in the city resulting in the expansion of peri-urban informal settlements. All the learners interviewed, except for one, indicated that working on the computers at the school was their first encounter with computers in their lives. The one learner indicated that he had played games on a computer of a friend whom he had visited in the city.

\section{Results}

Findings from one early lesson

\section{Description of lesson}

The following is a description of observation of a lesson that Mr. U used to prepare learners for the mathematics examination. The lesson description follows the representations developed by Mills and Treagust (2003) and Hartley and Treagust (2006), namely, the intended, implemented, perceived and achieved lessons.

Mr. U's lessons took place in the computer centre. He was in the centre before the class started so that he could prime the computer terminals - the server needed to be switched on - followed by the individual terminals. Mr. U described this process as time-consuming; there was little time available between lessons because the computer centre was shared between the mathematics and physical science teachers. Only 10 of the 15 terminals could be used for mathematics as the centre only had one licence for the CAMI program. Each licence allowed a maximum of ten computers to be linked to the server. 


\section{$\underline{\text { Intended lesson }}$}

Mr. U had a double period session with one of his Grade 12 mathematics classes. $\mathrm{He}$ indicated that he planned to use the computer centre to test learners about work completed in the normal classroom. He could only manage to use the centre once or twice a week for each of his classes as allowed on his time-table. The lesson planned for this particular session was to start out with simple factorisation leading to the use of the quadratic formula. The mark that learners would obtain counted towards their year mark. Mr. U indicated that he would monitor each learner's progress on the CAMI program as each learner logged in under his or her own name. This was possible since the computer flashed after a few minutes if learners took too long to answer a particular item (question). Each learner would be given a maximum of five items to complete.

\section{$\underline{\text { Implemented lesson }}$}

As learners came into the centre, they were allowed to sit at the entrance. Mr. U reminded the learners of the process that they normally followed. The first 10 learners were then each seated at a terminal and were told to $\log$ in. They were directed to the relevant section and were told to start. Appendix 1 shows a representation of the computer lesson on factorisation and shows examples that learners had to work through. Each learner carried with them a pen and paper and started by reading the problem on the computer and answering the items, for example one item under the factorisation test (at the first difficulty level) required learners to factorise the following quadratic equation: $x^{2}+5 x+6=0$. The computer provided two sets of brackets and learners had to complete the contents, in this items the correct solution was $(x+6)(x-1)$. Learners were then required to give the values for $x$, which for this item were $x=-6$ or $x=1$. In the next item, the difficulty level was increased with, for example, the addition of a coefficient to the first term of the equation. The learners were allowed a certain amount of time at a terminal to complete an item before the computer flashed they were told to continue to the next item. When learners completed answering an item, they automatically moved on to the next one. Learners who completed their five items were replaced by the learners waiting who were frantically going through their notes. 
When the test session ended, learners were allowed to work on the computers in groups and discussion ensued on the sections dealing with factorisation and using formulae and the missed chances for successful solutions. The group sessions had a number of learners around each of the 10 available computers. They were directed to the computer to start answering the section on factorisation followed by exponential and quadratic equations. Both teachers encouraged learners in groups to interact with one another and that they should show one another how they went about solving problems related to the syllabus. Teachers intervened in groups when there was no consensus about the approach to a problem or when learners were not clear about how to proceed between different steps when answering a problem. Teachers also used their time to assist the academically weaker learners.

\section{Perceived lesson}

Learners indicated that they enjoyed the sessions when they got to use the computers to see if they understood what was taught in class. The following were some feedback obtained from learners who were interviewed after the lesson:

Using the computer is important to test how quickly you can answer. It is almost like an examination when you are under pressure.

Learner 1

The testing with computer is not so nice. [But] I like using the computer to work on my own and at my own time.

Learner 2

I cannot think so fast, especially when Mr. U is looking over my shoulder. Learner3 I have no problem with using the computer, even in a test. We will have to learn to use the computer anyway, so now is a good time.

Learner 4

The computer is just used to test if we know our work. Mr. U explains the work well, and we can always ask him. He is always in the computer centre during intervals.

Learner 5

Testing with the computer helps us know where we don't understand. For if I struggle, I will try and try until I get it right. Then I know it and can answer it again. This is how computer is a help.

Learner 6

On the whole, learners expressed their satisfaction with using the computer which they saw as integral to their learning as pointed out by learners 4 and 6 . Some learners considered the pressure that they are put under as good (Learner 1) because this represented the pressure that they would experience under examination conditions; other learners saw the combined pressure of working on the computer and the teacher monitoring their progress as limiting or inhibiting (Learner 3). The role that teachers 
played still remained central to the classroom environment as expressed by Learner 5, who regarded the teacher as the interactive resource that could be approached should they require additional assistance. Learner 2 expressed the view that working on the computer individually still suited some learners.

\section{Achieved lesson}

The key outcome of this lesson was that learners were tested for their understanding of factorisation and using the quadratic formula by completing a test on the computer. Learners showed a great willingness and acceptance for a test of this nature. Because it was a test, no interaction took place between learners but they generally agreed to the test being a measure of their ability in factorisation. The lesson also led to some learners examining their own abilities in the two selected topics which resulted in many of them going back to these sections on the computer. The test also placed both teachers in the position of determining which learners still had problems with the tested areas, and the kind of remedial work or revision programme that needed to be structured. The outcomes of the test contributed towards the year mark of learners which eventually determined their achievement in the final examination.

General comments on the implementation, perception and achievement of lessons

There were a number of teachers utilising the centre for Grade 12 mathematics and physical science, which potentially caused a clash of time-tables should all of them decide to use the computer centre for all of their lessons. To solve this problem the teachers planned their annual timetable to allow for double periods during which time the centre could be used and so they took turns to use the computer centre. The computer programs were mostly used for reinforcement for what was already taught in the class. These sessions would also be planned around a particular topic that would provide learners with the opportunity to hone their ability to work quickly and accurately. The centre was therefore not used as a classroom in the strict sense of the word, but as an additional resource centre. The mathematics program also was used to track the progress of learners for each topic. This tracking, teachers claimed, allowed them to select their revision programmes in order to address problem areas. Learners would come during intervals, when they had a free opportunity and after school, to 
work on the computers. Unfortunately, during vacation periods computers have to be removed from the centre and locked away as they are vulnerable to theft.

\section{Findings from the learning environment questionnaire}

A total of 49 learners from across the three Grade 12 mathematics classes completed the CALEQ. The CALEQ was used after the first year to obtain learners' perceptions and experience for this period. This was their first exposure to CAL and the CALEQ data after one year would serve as a baseline to inform further CAL implementation. Table 2 represents a summary of the standard deviation and mean item scores of each scale of the CALEQ. The Material Organisation scale had the highest standard deviation for the actual version of the CALEQ and the Involvement scale had the highest for the preferred version which reflected the largest variation of responses to the two versions of the instrument. The Learning Assessment scale and the Investigation scale had the lowest range of responses for both the actual and preferred formats of the instrument respectively. The mean scores of all the scales were above 3 [between sometimes (3) and often (4)] which indicated a positive perception of the computer-assisted learning environment by the learners. These findings were also reported by other researchers over the past few decades (Geban, Askar, \& Özkan, 1992, Tao, 2004).

\section{PLACE TABLE 2 ABOUT HERE}

When comparing the item mean scores of the six scales for the actual and preferred formats of the instrument, as indicated by Figure 1, all six scales of the actual version were found to have relatively similar item means. The Integration scale had the highest item mean which reflected that learners perceived the integration of computer lessons within the daily teaching and learning activities of teachers and learners as positive. The Open-Endedness scale had the lowest item mean indicating that learners perceived less open-endedness in their computer-assisted classes than the other dimensions.

PLACE FIGURE 1 ABOUT HERE 
The preferred version, that represented learners' perceptions, pointed towards a more positive computer-assisted learning environment. The findings indicated that the learners' mean item scores were higher than the actual means on four scales Involvement, Open-Endedness, Learning Assessment and Integration. These results indicate that learners prefer to be more involved, to have more open-endedness in their classes, to increase the learning assessment opportunities and to have a greater level of integration of computers in their mathematics classes.

The preferred scores for the Learning Assessment scales were the highest, indicating a greater preference for monitoring their own learning. This result is consistent with what was reported in the qualitative data. Learners wanted more computers at their centres and also emphasised their individual needs to have a computer of their own in order to assess their own learning. The higher scores for this scale on the preferred level could possibly be attributed to the fact that learners, in most instances, only worked on computers about once a week and expressed a desire to have enough computers to work on their own. The majority of learners linked the monitoring of their learning to learning on their own, pointing out that the additional exercise they gained from working on the computers improved their problem-solving skills and the speed and accuracy with which they worked. This improvement in problem-solving supports the research findings of Yalcinalp, Geban \& Ozkan (1995) who reported that the continued use of computers assisted learners in improving their problem-solving skills.

The learners also preferred to have a greater integration of computers in their daily classes. These preferences also could be linked to the implementation strategy at this school because learners, who used the computers on average once a week, would prefer greater integration of computers in their lessons. The increase in the scores of the open-endedness scale from actual to preferred format was supported by indications from learners that they wanted greater control over the sections that they could explore on the computer. The current strategy allows them to only work those areas of mathematics curriculum determined by the teacher.

For the Involvement scale, the preferred mean item scores were higher than the actual version. Most learners were satisfied with the way that they were involved in 
computer-assisted classes and indicated that they readily participated in discussions with fellow learners and with the teacher about the work on the computer. Reports from the interviewed teachers showed that more learners were willing to share their ideas and thoughts on topics that were based on the work from the computer but were reluctant to participate in the formal class. Learners were encouraged by their teachers to interact with each other while answering questions on the computer. This interaction allowed greater involvement in the classroom tasks because learners had to work in groups around the limited number of computers. Some learners reported cooperative relationships with their peers, which were also encouraged by a number of researchers (Bennett 1992; Oshima et al. 2004; Tao 2004; Yalcinalp et al. 1995).

The scores for the Investigation and Material Organisation scales indicated lower levels of these two scales for the actual version of the CALEQ and then even lower scores for the preferred version. However, the trend of these results indicated that learners preferred less investigative activities and less organisation in the computer centre. Indeed, many learners indicated that they did not like to work out problems with the teacher standing behind their backs looking over their shoulder. Some learners considered it as distracting "I cannot think so fast when Mr. U is looking over my shoulder", and suggested that they preferred to call the teacher when he was needed. Also, learners indicated that they preferred the situation where the teacher worked out the problems on the board and then they could just follow what the teacher was doing, instead of struggling with problems on their own. These situations possibly could be attributed to the lower investigation preference by learners. The lower mean item scores for Material Organisation could possibly be attributed to the fact that the computer centre was used only for additional exercises and reinforcement of work already taught in class. During the interviews, learners indicated that they wanted to work on the computers as individuals which could imply that they preferred a less structured approach in the computer centre.

Most learners who were interviewed related that the inclusion of the computer centre as part of mathematics periods took place mostly once and sometimes twice a week. The computer centre was used as a resource centre where additional reinforcement of the work taught in the classroom took place. The everyday teaching of mathematics and physical science would thus take place in the classroom without the inclusion of 
the programs on the computers. Consequently, the computer-assisted classes were separate from the lessons that dealt with a particular topic; when learners attended the computer centre during a double period, they would be referred to the topic covered in the classroom.

Learners indicated that they were satisfied with the way that their classes on the computers were conducted and acknowledged that their level of involvement in the discussions that emanated from their interactions with the computers and fellow learners, were adequate. They participated readily in discussions with both the teacher and their fellow learners; teachers allowed learners the freedom to interact with one another about problems on the computer. These learners also indicated the programs were reasonably user-friendly and allowed easy access to the different parts of both subjects.

...in mathematics we can jump to problems of different difficulties...we did struggle initially with using some of the keys, but we got used to them very quickly... working with these computers are no big deal.

Many of these learners indicated that they made use of the computers during intervals or when they had a free session, for example, when a teacher was absent. Learners also pointed out that Mr. $\mathrm{U}$ was in the computer centre during lunch intervals and that he allowed them during this time the freedom to explore the sections with which each individual had difficulty.

Learners also pointed out that the teachers encouraged them to work out problems on their own but also encouraged them to share their way of working out problems with fellow students who were struggling. Learners emphasised that they were notified at the beginning of the year to bring their notebooks to the computer centre because they were not allowed to sit at a terminal without having an additional resource to refer to. They also were required to write down problems that were presented on the computer and calculate the answers separately before going back to the computer. As pointed out by one learner:

I always have scrap paper to work out. When I get the answer we will then put it in the computer. If the answer is right, ... I mean the computer says 'okay', then I can write it in my notebook. I don't have a textbook you see.. so now I make lots of sums [problems] in my notebook. 
Some of the learners interviewed also indicated that they were not always sure whether the exercise that they got on the computer would lead to them faring better in the matriculation examination. Some felt that it made no difference if they worked on the computer or were just taught in the classroom.

We get our classes, then we have to also go once a week to work on computers. ...the work on the computers are the same as what we get in the class. Anyway, there's not enough computers so we sit and talk and work out problems. We can do the same in the class.

A few learners also had negative feelings about the computers because in their opinion it took too long for there were not sufficient computer terminals to have one for each student.

Most of the interviewed learners indicated that they considered the extra exercise from answering questions on the computer to be helpful to their learning. They also pointed out that when they assisted one another in working out problems they were improving their own problem-solving skills. One learner related that:

We are also helping one another, and by helping one another we are also learning at the same time. I can think with one problem in Algebra, I gave an answer which the computer accepted. When ...(friend)... asked me how to work it out, I showed him in my book. It helped me to work out the next question on the computer, and I remembered it in a test we wrote. So it helps to help each other.

Other learners indicated that the regular exercise they got on the computer helped them with working out problems more quickly and more accurately. Again a few learners pointed out that if there were more computers, their learning would improve because they would be working on problems on their own and learning in their own way. They considered working on their own as important because:

I write the exam on my own and would like to work on my own... My marks in Maths did increase but I still need to work harder in the Physics.

In a response to a question by the first author to the interviewees, all learners agreed that learning of the two subjects was much better than in their previous grades and that the improved learning was at least in part due to their interactions with computers. 
Most learners interviewed linked their interactions in the computer centre with an improvement in learning. These interactions occurred between learners, learners and the computer, and learners and their respective teachers. They found these interactions useful because it gave them a chance to discuss the problems in groups where they did not feel threatened by the presence of a person representing authority. The teacher became involved when he was called upon to provide assistance where consensus could not be reached. Learners stressed that because they were only allowed to work on the computer once a week during school hours, they considered the time spent on the computer as essential to sharpen some of their skills in answering problems. In one of the groups, a learner stated that:

Sometimes we challenge each other to work out problems on our own and to punch in the answer in the computer. ...We keep our calculations covered like and also wait until one person gets the right answer. We then compare with everyone in the group to see who also get it right. We see who gets the most right answers.

However, some learners did argue for a reduction in interactions between learners and that they should be allowed to work on the computers as individuals to cater for their individual needs. Interviewed learners on the whole wanted more computers. They claimed that the computer centre could hold more than 40 computers and that this would go far to assist them in the two subjects. It would also help those who wanted to work more as individuals while a group of learners could still work jointly on one computer. Learners also wanted more and different programs to be included on the computer. They stressed that the programs were too curriculum-related and that more interactive programs should be made available. Other subjects such as geography, accounting and English also should be included on the computers. Learners also mentioned that they could only use 10 of the 15 available computer terminals for mathematics due to the licence agreement with the CAMI mathematics program and that they wanted this licence to be extended so that all computer terminals were available to use in their mathematics lessons.

\section{Summary and recommendations}

This paper presented one case study of a peri-urban school which formed part of a wider study into computer-assisted learning at disadvantaged schools in the Western 
Cape Province of South Africa. This study responded to a national plea to provide support to learners and teachers in mathematics, science and languages in order to meet the challenges and demands of the new information and communication technologies.

A number of key recommendations to mathematics practitioners in disadvantaged schools have emerged from this study for implementation of an effective CAL strategy. The findings of this study pointed out that the use of computers to support the teaching of mathematics served as a positive step as it increased learners' involvement in the mathematics classroom but some researchers (Cornu 1995; Hakkarainen 2003) indicated that although the computer is able to provide new opportunities for the teaching of mathematics and science, the onus is on teachers and educators to overcome the difficulties of using these activities. The findings in this study indicated that the use of computers gave learners more exercise in problem solving in mathematics, and provided them the opportunity to assess their own learning and understanding of the different aspect in the mathematics curriculum. These findings are supported by researchers (Lavonen and Aksela 2003; Snir et al. 2003; Soderberg 2003) who reported that emergent technologies can illuminate the structure and behaviour of complex scientific phenomena that have been difficult for students to understand using traditional modes of instruction.

Given the demand for the limited resource, learners articulated a strong recommendation for more computers to be made available that would allow them to also work individually and to spend more time on the computer. It is on the basis of these preliminary findings that the following recommendations were made explicit, namely (1) provision of the sufficient IT resources to support the everyday teaching of mathematics, (2) training of teachers to maximise the use of the computer as a tool to assist the teaching and learning of mathematics as a subject, (3) that the use of computers in the teaching of mathematics be started much earlier than Grade 12 to give learners the opportunity to understand the role of computers in their learning environment, (4) that the diagnostic potential of computer programs be exploited to identify learner misconceptions in the mathematics curriculum, and (5) that the use of computers and various software programs could serve as interim support to rural and 
other disadvantaged schools in South Africa where resources such as textbooks and trained educators are still seriously lacking.

The study also provides baseline data for future research in computer-assisted learning environments at disadvantaged schools in South Africa and the role computers could play in supporting teachers and learners in a key subject like mathematics.

\section{References}

Aldridge, J.M. \& Fraser, B.J. (2008). Outcomes-focussed learning environment: determinants and effects. Rotterdam, The Netherlands: Sense Publishers.

Aldridge, J.M., Fraser, B.J. \& Laugksch. (2011). Relationship between the schoollevel and classroom-level environment in secondary schools in South Africa. South African Journal of Education, 22, 37-55.

Aldridge, J.M. Laugksch, R.C. \& Fraser, B.J. (2006). School-level environment and outcomes-based education in South Africa. Learning Environments Research: An International Journal, 9, 123-147.

Aldridge, J.M. Laugksch, R.C., Seopa, M.A. \& Fraser, B.J. (2006). Development and validation of an instrument to monitor the implementation of outcomes-based learning environments in science classrooms in South Africa. International Journal of Science Education, 28, 45-70.

Aldridge, J.M., Fraser, B.J. \& Sebela, M.P. (2004). Using teacher action research to promote constructivist learning environments in South Africa. South African Journal of Education, 24, 245-253.

Bennett, J. P. (1992). Computers in mathematics education: A 'not really for the researcher' review of recent unique findings. School Science and Mathematics, 92(1), 38-39.

Buerck, J.P., Malmstrom, T. \& Peppers, E. (2003). Learning environments and learning styles: Non-traditional student enrolment and success in an internetbased versus a lecture-based computer science course. Learning Environments Research: An International Journal, 6 (2), 137-155. 
Cornu, B. (1995). New technologies: integration into education. In D. Watson \& D. Tinsley (Eds.), Integrating information technology into education. London: Chapman \& Hall.

Fisher, D.L. \& Fraser, B.J. (2003). Emergence of learning environment research in South Africa: Editors' introduction. Learning Environments Research, 6: 229230.

Fraser, B. J. (1990). Individualised classroom environment questionnaire. Melbourne, Victoria: Australian Council for Educational Research.

Fraser, B.J. (1998). Science learning environments: Assessment, effects and determinants. In B.J. Fraser \& K.G. Tobin (Eds.), International handbook of science education (pp. 527-564). Dordrecht, The Netherlands: Kluwer.

Fraser, B. J., McRobbie, C.J. \& Fisher, D.L. (1996). Development, validation and use of personal and class forms of a new classroom environment instrument. Paper presented at the Annual meeting of the American Educational Research Association, New York.

Fraser, B. J., McRobbie, C.J. \& Giddings, G.J. (1993). Development and crossnational validation of a laboratory classroom environment instrument for senior high school science. Science Education, 77(1), 1-24.

Geban, Ö., Askar, P., \& Özkan, I. (1992). Effects of computer simulations and problem solving approaches on high school students. Journal of Educational Research, 86, 5-10.

Hakkarainen, K. (2003). Emergence of progressive-inquiry culture in computersupported collaborative learning. Learning Environments Research: An International Journal, 6 (2), 199-220.

Hartley, M.S. (2002). The effectiveness of an outreach programme in science and mathematics for disadvantaged Grade 12 students in South Africa. Curtin University of Technology, Perth, Australia.

Hartley, M.S., \& Treagust, D.F. (2006). Learning physical science in a rural South African school: A case study of student perceptions of the value of computerassisted learning. Science Education International, 17, (1), 13-29.

Hartley, M.S., Treagust, D.F. \& Ogunniyi, M.B. (2008). The application of a CAL strategy in science and mathematics for disadvantaged Grade 12 learners in South Africa. International Journal of Educational Development, 28, 596-611. 
Lavonen, J., Aksela, M., Meisalo, V., 2003. Designing a userfriendly microcomputerbased laboratory package through the factor analysis of teacher evaluations. International Journal of Science Education 25 (12), 1471-1487.

Maor, D., \& Fraser, B. J. (1993). Use of classroom environment perceptions in evaluating inquiry-based computer learning. The study of learning environments, $7,57-71$.

Maor, D., \& Fraser, B. J. (1996). Use of classroom environment perceptions in evaluating inquiry-based computer learning. International Journal of Science Education, 18, 401-421.

Mills, J., \& Treagust, D. F. (2003). Using projects to teach structural engineering. Australian Journal of Structural Engineering, 4 (3) 211- 220.

Nunnally, J. (1978). Psychometric theory. New York: McGraw-Hill.

Oshima, J., Oshima, R., Murayama, I., Inagaki, S., Takenaka, M., Nakayama, H., \& Yamaguchi, E. (2004). Design experiments in Japanese elementary science education with computer support for collaborative learning: hypothesis testing and collaborative construction. International Journal of Science Education, 26(10), 1199-1221.

Snir, J., Smith, C., Raz, G., 2003. Linking phenomenon with competing underlying models: a software tool for introducing students to the particulate nature of matter. Science Education, 87, 794-830.

Soderberg, P., Price, F., 2003. An examination of problem-based teaching and learning in population genetics and evolution using EVOLVE, a computer simulation. International Journal of Science Education, 25 (1), 35-56.

Tao, P-K. (2004). Developing understanding of image formation by lenses through collaborative learning mediated by multimedia computer-assisted learning programs. International Journal of Science Education, 26 (10), 1171-1197.

Teh, G. P., \& Fraser, B. J. (1993). A study of computer-assisted learning environments in Singapore. The Study of Learning Environments, 7, 42-56.

Teh, G. P., \& Fraser, B. J. (1994). An evaluation of computer-assisted learning in terms of achivevement, attitudes and classroom environment. Evaluation and Research in Education, 8, 147-161.

Walker, S.L. \& Fraser, B.J. (2005). Development and validation of an instrument for assessing distance education learning environments in higher education: The 
distance education learning environments survey (DELES). Learning Environments Research: An International Journal, 8 (3), 289-308.

Yalcinalp, S., Geban, Ö., \& Özkan, I. (1995). Effectiveness of using computerassisted supplementary instruction for teaching the mole concept. Journal of Research in Science Teaching, 32(10), 1083-1095. 


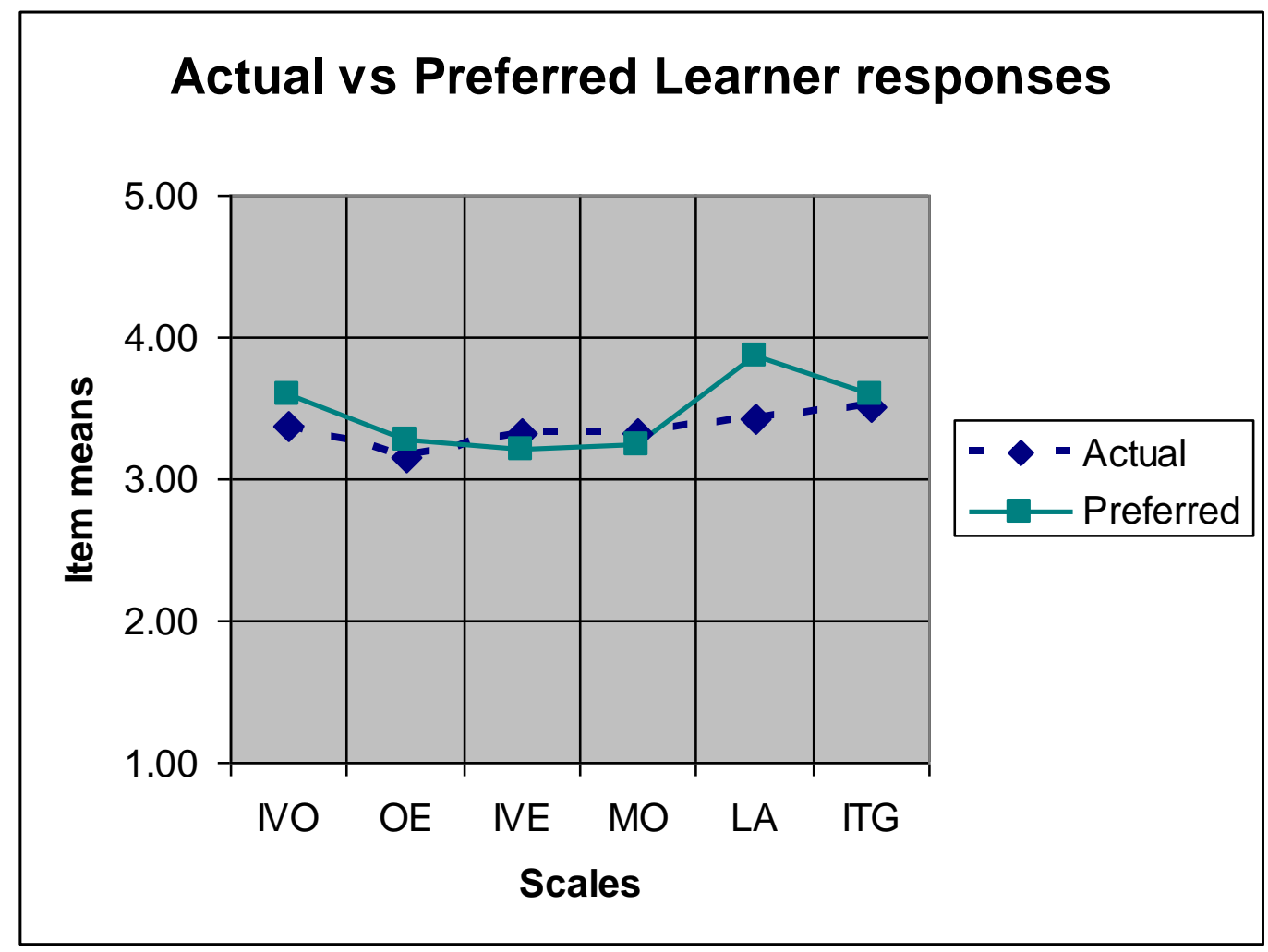

Figure 1

A comparison of the item means obtained from the actual and preferred forms of CALEQ of learners $(n=49)$ 
Table 1

Descriptive information for the CALEQ scales

\begin{tabular}{|c|c|c|}
\hline Scale Name & Description & Sample item \\
\hline Involvement & $\begin{array}{l}\text { Extent to which learners have } \\
\text { attentive interest, participate in } \\
\text { discussions, perform additional } \\
\text { work, and experience the CAL } \\
\text { classes }\end{array}$ & $\begin{array}{l}\text { I am asked to explain how } \\
\text { I solve problems (+) }\end{array}$ \\
\hline $\begin{array}{l}\text { Open- } \\
\text { endedness }\end{array}$ & $\begin{array}{l}\text { Extent to which an open ended } \\
\text { approach is adopted in the CAL } \\
\text { classes }\end{array}$ & $\begin{array}{l}\text { I must answer questions in } \\
\text { a prescribed way (-) }\end{array}$ \\
\hline Investigation & $\begin{array}{l}\text { Extent to which learner is } \\
\text { encouraged to engage in the } \\
\text { learning process }\end{array}$ & $\begin{array}{l}\text { I find out answers to } \\
\text { questions by doing } \\
\text { investigations (+) }\end{array}$ \\
\hline $\begin{array}{l}\text { Material } \\
\text { Organization }\end{array}$ & $\begin{array}{l}\text { Extent to which CAL classes are } \\
\text { organized and computer } \\
\text { hardware and software are } \\
\text { adequate }\end{array}$ & $\begin{array}{l}\text { The computer programs are } \\
\text { hard to use (-) }\end{array}$ \\
\hline $\begin{array}{l}\text { Learning } \\
\text { assessment }\end{array}$ & $\begin{array}{l}\text { Extent to which the learner can } \\
\text { assess his understanding of } \\
\text { subject content }\end{array}$ & $\begin{array}{l}\text { I have improved my ability } \\
\text { to solve problems by using } \\
\text { the computer }(+)\end{array}$ \\
\hline Integration & $\begin{array}{l}\text { Extent to which the computer is } \\
\text { included as a tool in daily } \\
\text { teaching of mathematics and } \\
\text { physical science }\end{array}$ & $\begin{array}{l}\text { The computer work is } \\
\text { integrated with the regular } \\
\text { science and mathematics } \\
\text { class work. }(+)\end{array}$ \\
\hline
\end{tabular}

Note: Items designated (+) are scored 1, 2, 3, 4 and 5, respectively, for the responses Almost Never, Seldom, Sometimes, Often, Very Often. Items designated (-) are scored in the reverse manner. The same scoring procedures apply to both actual and preferred formats of the CALEQ. 
Table 2

Alpha reliability, Average Item Mean, Standard Deviation and t-value for the actual and preferred versions of the CALEQ $(n=49)$

\begin{tabular}{|c|c|c|c|c|c|c|}
\hline Scale & $\begin{array}{l}\text { No. of } \\
\text { items }\end{array}$ & Form & $\begin{array}{c}\text { Alpha } \\
\text { reliability }\end{array}$ & $\begin{array}{c}\text { Average } \\
\text { Item } \\
\text { Mean }\end{array}$ & $\begin{array}{l}\text { Scale } \\
\text { Std. } \\
\text { Dev. }\end{array}$ & t-value \\
\hline $\begin{array}{l}\text { Involvement } \\
\text { (IVO) }\end{array}$ & 8 & $\begin{array}{c}\text { Actual } \\
\text { Preferred }\end{array}$ & $\begin{array}{l}.64 \\
.79\end{array}$ & $\begin{array}{l}3.37 \\
3.59\end{array}$ & $\begin{array}{l}4.95 \\
6.53\end{array}$ & 1.56 \\
\hline $\begin{array}{l}\text { Open- } \\
\text { Endedness (OE) }\end{array}$ & 8 & $\begin{array}{c}\text { Actual } \\
\text { Preferred }\end{array}$ & $\begin{array}{l}.51 \\
.59\end{array}$ & $\begin{array}{l}3.15 \\
3.27\end{array}$ & $\begin{array}{l}4.79 \\
5.13\end{array}$ & 0.92 \\
\hline $\begin{array}{l}\text { Investigation } \\
\text { (IVE) }\end{array}$ & 8 & $\begin{array}{c}\text { Actual } \\
\text { Preferred }\end{array}$ & $\begin{array}{l}.61 \\
.53\end{array}$ & $\begin{array}{l}3.33 \\
3.20\end{array}$ & $\begin{array}{l}5.01 \\
4.49\end{array}$ & 1.07 \\
\hline $\begin{array}{l}\text { Material } \\
\text { Organisation } \\
(\mathrm{MO})\end{array}$ & 8 & $\begin{array}{c}\text { Actual } \\
\text { Preferred }\end{array}$ & $\begin{array}{l}.64 \\
.64\end{array}$ & $\begin{array}{l}3.32 \\
3.24\end{array}$ & $\begin{array}{l}6.30 \\
5.79\end{array}$ & 0.47 \\
\hline $\begin{array}{l}\text { Learning } \\
\text { Assessment } \\
\text { (LA) }\end{array}$ & 8 & $\begin{array}{c}\text { Actual } \\
\text { Preferred }\end{array}$ & $\begin{array}{l}.54 \\
.63\end{array}$ & $\begin{array}{l}3.43 \\
3.87\end{array}$ & $\begin{array}{l}4.66 \\
4.73\end{array}$ & $4.03^{*}$ \\
\hline $\begin{array}{l}\text { Integration } \\
\text { (ITG) }\end{array}$ & 8 & $\begin{array}{c}\text { Actual } \\
\text { Preferred }\end{array}$ & $\begin{array}{l}.65 \\
.70\end{array}$ & $\begin{array}{l}3.51 \\
3.59\end{array}$ & $\begin{array}{l}5.25 \\
5.67\end{array}$ & -0.6 \\
\hline
\end{tabular}

$* \mathrm{p}<0.01$ 
Appendix 1. Representation of the computer lesson on factorisation

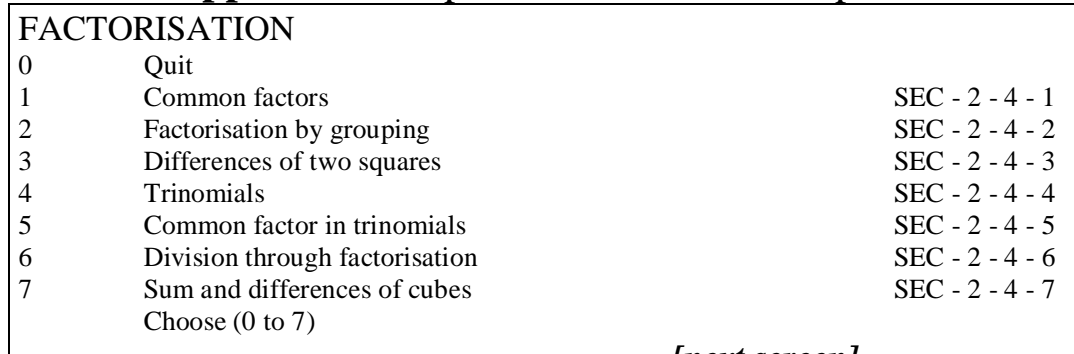

Common factors

Factorise the following expressions:

Level A

$=2 \mathrm{p}^{2}-5 \mathrm{pr},()$

Level B

Level C

$=\frac{12 \mathrm{f}^{4}-42 \mathrm{f}^{3} \mathrm{p}^{3}}{}=-(\mathrm{C}$

$\left.=\frac{7 q^{4}-3 q^{3}}{-}\right)$

Level D

Level E

$$
\left.=-56 g^{4} r^{3} y^{3}-16 g^{3} r^{7} y^{7}\right)
$$

Hint: Remove the common factor.

Press Enter to mark, A - E for level, $\mathrm{H}$ for Help, $\leftarrow$ to erase.

Factorisation by grouping

Factorise the following expressions:

Level A

Level C

\begin{tabular}{|c|c|c|}
\hline fr - & $-f x+n x$ & \\
\hline $\begin{array}{l}= \\
=r\end{array}$ & )+ & ) \\
\hline
\end{tabular}

Level B

\begin{tabular}{|c|}
\hline $\mathrm{k}^{2}-\mathrm{k}(8+\mathrm{r})+8 \mathrm{r}$ \\
$(\mathrm{c})$ \\
\hline
\end{tabular}

Factorise the following expression:

\begin{tabular}{|c|c|}
\hline \multicolumn{2}{|c|}{$10 n^{5}-12 n^{4} z+15 n z^{4}-18 z^{5}$} \\
\hline$=$ & )$+\ldots(\quad)$ \\
\hline$=($ & )( \\
\hline
\end{tabular}

Difference of two squares

Factorise the following expressions:

Level A

$=\left(\begin{array}{ll}49-\mathrm{t}^{2} \\ =\end{array}\right)(\quad)$

Level B

$25 \mathrm{p}^{2}-\mathrm{q}^{2}$
$=(\quad)(\quad)$

Level C

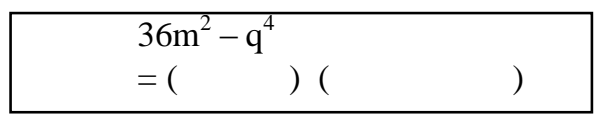

Level D
$\left.\begin{array}{rl}\hline & 9 n^{12}-36 y^{4} \\ = & (\end{array}\right)\left(\begin{array}{l} \\ \hline\end{array}\right.$

Level E

$16 \mathrm{k}^{16} \mathrm{q}^{12}-36 \mathrm{x}^{16}$
$=(\quad))(\quad)$

Complete the first bracket.

Complete the second bracket 


\section{Trinomials}

Factorise the following expressions:

Level A

$$
\begin{aligned}
& \mathrm{g}^{2}+9 \mathrm{~g}+18 \\
& =(\quad)(\quad)
\end{aligned}
$$

Level B

$\mathrm{q}^{2}-4 \mathrm{q}+4$
$=(\quad)(\quad)$

Level C

$$
\begin{aligned}
& 20 \mathrm{f}^{2}-39 \mathrm{f}+18 \\
& =(\quad)(\quad)
\end{aligned}
$$

Complete the first bracket

Complete the second bracket

\section{Common factor in trinomials:}

Factorise the following expressions:

Level A

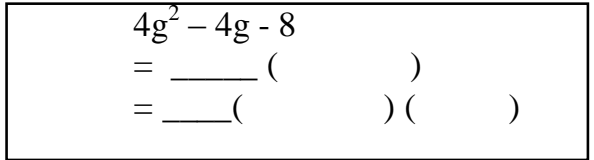

Level C

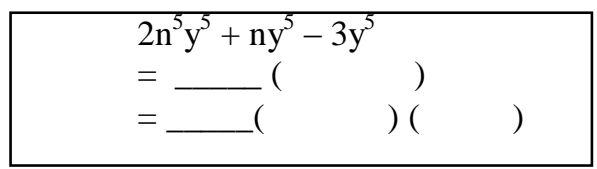

Level E

$6 \mathrm{~g}^{6} \mathrm{x}^{4}+14 \mathrm{~g}^{5} \mathrm{x}^{4}+8 \mathrm{~g}^{4} \mathrm{x}^{4}$
$=\ldots()$
$=\ldots$

Hints:

Take out the common factor.

Write the remainder in descending order

Complete the first bracket

Complete the second bracket
Level B

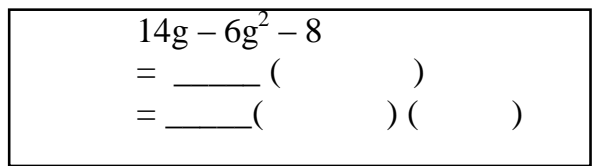

Level D

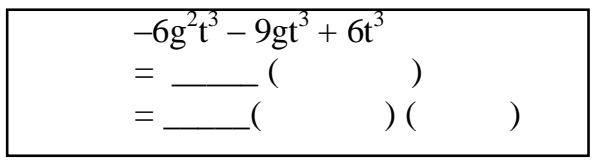

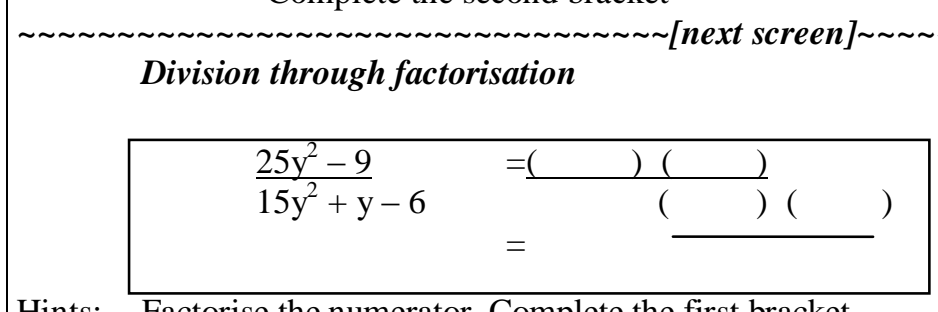

Hints: Factorise the numerator. Complete the first bracket.

Factorise the numerator. Complete the second bracket.

Factorise the denominator. Complete the first bracket.

Factorise the denominator. Complete the second bracket

Cancel the common factor. Give the numerator.

Give the remaining denominator.

Sum and difference of cubes

Factorise the following expression:

$\mathrm{n}^{12}+8 \mathrm{y}^{12}$
$=(\quad)(\quad)$

$27 \mathrm{~g}^{6}+64 \mathrm{q}^{12}$
$=(\quad)(\quad)$

Hints: Complete the first bracket.

Complete the second bracket. 